\title{
THORACIC INTRADURAL EXTRAMEDULLAR ARACHNOID CYST IN AN ADULT: CASE REPORT AND REVIEW OF THE LITERATURE
}

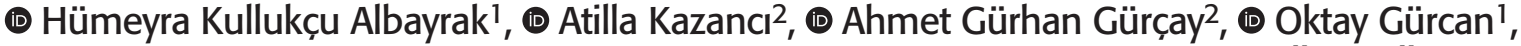 \\ (1) Mehmet Özgür Özateș1
}

\author{
${ }^{1}$ Ankara City Hospital, Clinic of Neurosurgery, Ankara, Turkey \\ ${ }^{2}$ Yıldırım Beyazıt University, School of Medicine, Department of Neurosurgery, Ankara, Turkey
}

Spinal intradural arachnoid cysts are rare and primarily benign lesions. These cysts are typically located posterior to the spinal cord in the middle to lower thoracic spinal legion. They occur more frequently during adolescence or in early adult life. The true mechanism of arachnoid cysts development is not yet known. Possible mechanisms proposed include congenital, inflammatory arachnoidal adhesions, and, arachnoiditis secondary to subarachnoid haemorrhage, local anaesthetics and contrast agents, injury of the spinal column. Depending on the location, size, and mechanism of origin, the clinical course varies between asymptomatic, incidentally-diagnosed cases to severe myelopathy and/or radiculopathy. The final diagnosis is based on combined imaging, intra-operative, and histopathological findings. In the differential diagnosis cystic tumours, ependymal cysts, neurenteric cysts, teratogenic cysts and epithelial cysts should be considered. Surgical approach is usually indicated for symptomatic patients or progression in size through excision in the epidural space/fenestration in the intradural space. The basic surgical principle is the removal of spinal compression with cyst excision. Shunts may be considered in recurrent cysts. Because of its rare diagnosis mostly case reports have been reported in the literature. Thus, we report an adult patient with thoracic intradural extramedullary arachnoid cyst with a complaint of dorsalgia who responded well to Gabapentin treatment along with literature review.

Keywords: Arachnoid cyst, thoracic, gabapentin, dorsalgia

\section{INTRODUCTION}

Spinal intradural arachnoid cysts are rarely diagnosed in patients during adulthood and usually show symptoms before adolescence. They are fenestrated in most cases in order to relieve the spinal cord of tension. Most of the symptoms arise from the compression of the spinal cord, which in turn results in a variety of neurological deficits. Although symptomatic patients undergo surgery, a stable radiological examination of patients with no neurological deficit would allow for a more non-invasive follow-up. Furthermore, there is no evidence of a relationship between dorsalgia and arachnoid cysts.

\section{CASE REPORT}

A 48-year-old male patient visited our clinic complaining of a long-lasting upper-back pain. The patient had no significant history of trauma, previous surgery, infection or spinal anaesthesia. He complained of the upper-back pain extending to the neck, which was aggravated by physical activity and alleviated by resting. He had taken multiple non-steroidal anti-inflammatory drugs (NSAIDs) which did not significantly alleviate his pain. The result of his neurological examination was normal. A magnetic resonance imaging (MRI) of his thoracic vertebra without contrast enhancement revealed an arachnoid cyst at T4 level posterior to the spinal cord with cerebrospinal fluid (CSF) (Figure 1, 2). Since no abnormal neurological finding was observed, he was closely observed for other symptoms of neurological deficit; he was orally administered with $300 \mathrm{mg}$ Gabapentin thrice a day and called for a check-up 6 months later. After 6 months, no change was observed in the cyst size in response to Gabapentin. Therefore, he was continued on Gabapentin treatment and called for a check-up in 12 months.

\section{DISCUSSION}

Our study presents a case of a patient diagnosed with a spinal intradural arachnoid cyst based on MRI findings. Arachnoid

Address for Correspondence: Hümeyra Kullukçu Albayrak, Ankara City Hospital, Clinic of Neurosurgery, Ankara, Turkey E-mail: humeyrakullukcu@hotmail.com Received: 04.05.2020 Accepted: 05.05.2020

ORCID ID: orcid.org/0000-0003-0675-8288 


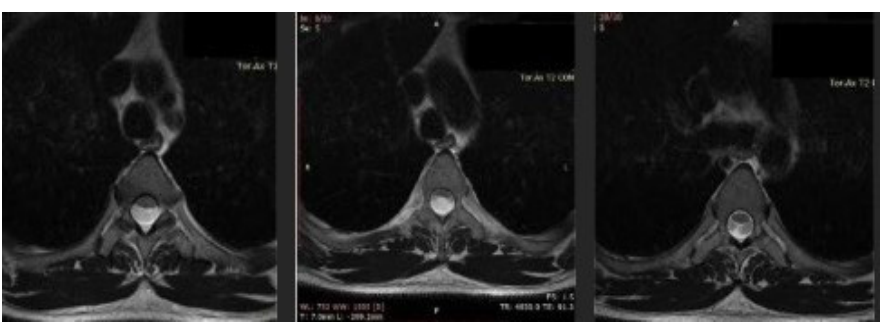

Figure 1. Axial views of T4 level perpendicular to the arachnoid cyst in $\mathrm{T} 2$ sequence showing the compression of the spinal cord from the posterior

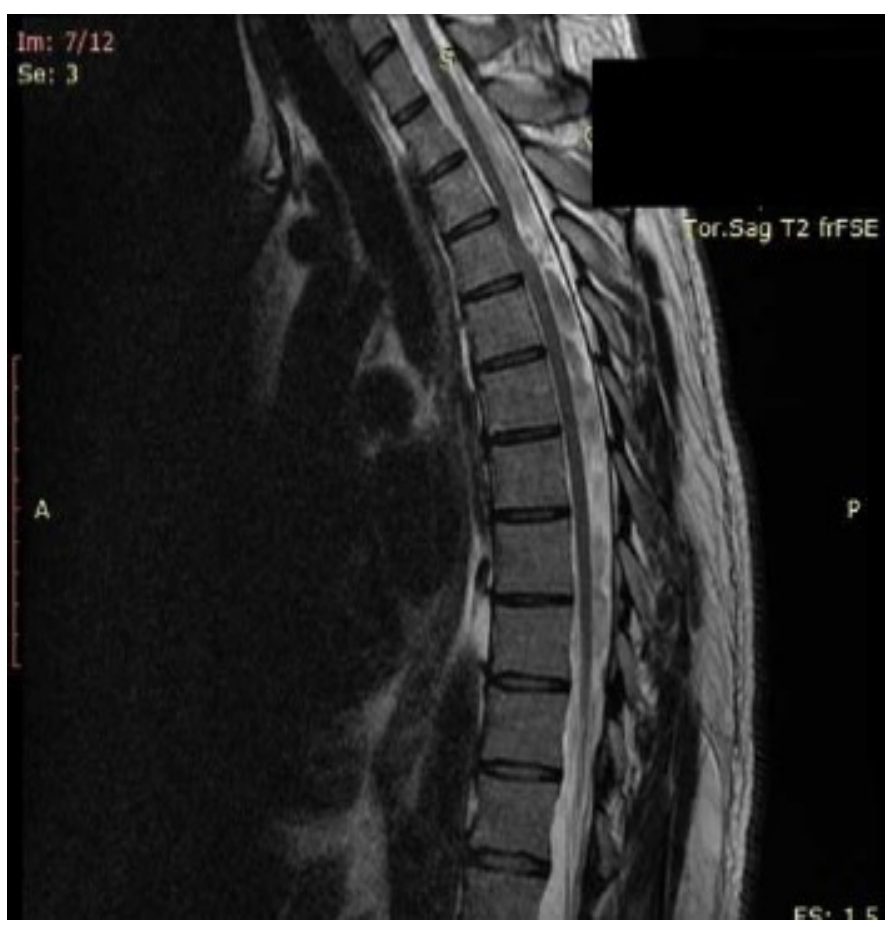

Figure 2. Sagittal view of the arachnoid cyst in T2 sequence cysts are characterised as well circumscribed cysts with an imperceptible border, displacing adjacent structures and following a CSF pattern-hyperintense on T2 with FLAIR suppression on the MRI. One of the differential diagnoses of arachnoid cysts is idiopathic spinal cord herniation, which detects a defect in the dura mater; this was not observed in this case. Additionally, neuroradiologists were consulted for their inputs on the case to reach a consensus. Spinal intradural arachnoid cysts may be diagnosed with or without neurological deficit. These pathologies are mostly located anterior to the spinal cord in the cervical region and posterior to the spinal cord in the thoracolumbar region ${ }^{(1)}$. The arachnoid cysts located in the intradural space of the thoracic region are rarely diagnosed in adults. Surgery is recommended for symptomatic patients, whereas a close follow-up of the neurological status, together with a radiological examination, is a more plausible option for asymptomatic patients.

There are many hypotheses postulating the underlying factors of arachnoid cyst development. Although it is thought to have a multifactorial cause, adhesions in the arachnoid mater after surgery or trauma is believed to disrupt the flow of CSF, leading to its accumulation in a contained space, thus forming an arachnoid cyst. Moreover, patients with coagulation disorders may have an asymptomatic haemorrhage in the intradural space, leading to adhesions in a similar manner ${ }^{(2)}$ Another hypothesis postulates an arachnoid mater herniation through congenital intradural defects with the pulsation of CSF. However, defects in arachnoid trabeculations may evolve over time following a similar mechanism. Although patients with spinal intradural arachnoid cysts have a strong family history and high rate of developing central nervous system abnormalities, congenital factors are also believed to play a major role(3). Patients usually complain of pain aggravation as a result of staying in an erect position for a prolonged time. Apart

Table 1. Previous reports of Thoracic Arachnoid Cysts

\begin{tabular}{|c|c|c|c|}
\hline Author & Average age (years) & Number of cases & Localisation \\
\hline Mohindra et al.(4) & $25(6-46)$ & 10 & C:3, T:5, L:1, S:1 \\
\hline da Conceição et al.(5) & 28 & 1 & $\mathrm{~T} 1-\mathrm{T} 12$ \\
\hline Rao et al. ${ }^{(7)}$ & 9 & 1 & $\mathrm{~T} 1-5$ \\
\hline Novegno et al. (8) & 31 & 1 & T11-12 \\
\hline Van Nuenen et al.(11) & 65 & 1 & $\mathrm{T7}$ \\
\hline Payera and Brühlhart ${ }^{(12)}$ & 33 & 1 & T11-L1 \\
\hline Kumar et al. ${ }^{(13)}$ & $40 \& 75$ & 2 & T3-5\&T5-7 \\
\hline Peruzzotti-Jametti et al.(14) & 53 & 1 & C1-T11 \\
\hline
\end{tabular}

C: Cervical vertebra, T: Thoracic vertebra, L: Lumbar vertebra 
from the pain experienced, most patients experience common symptoms such as hypoesthesia, ataxia and motor weakness as well as urinary symptoms. Myelopathic symptoms may arise due to the compression of the spinal cord. However, it is important to note that the cyst may disturb CSF flow, thus resulting in syringomyelia or similar symptoms where surgery becomes inevitable. Since symptomatic cysts are usually identified during childhood, their diagnosis in adults is usually rare. During the diagnosis of arachnoid cysts, cystic tumours, ependymal cysts, neurenteric cysts and teratogenic cysts, epithelial cysts must be differentiated (3).

Table 1 outlines the literature review of spinal intradural arachnoid cysts diagnosed in the thoracic region. All the patients in the previously reported cases have undergone surgery due to neurological deficits. In this case, the patient underwent a normal neurological examination and a tolerable amount of pain. Myofacial syndrome or radiculopathy in this patient was ruled out; therefore, his alleviation is unlikely to have a different aetiology even though it is unclear how Gabapentin relieved his symptoms. Therefore, no surgery was performed. However, widely used analgesics, such as NSAIDs, did not relieve the patient's pain. Gabapentin is routinely used for the treatment of neuropathic pain. Patients with chronic irritation of the nerve roots or with spondylotic symptoms have greatly benefited from Gabapentin. Although no case has reported the use of Gabapentin in the treatment of stable spinal intradural arachnoid cysts, this patient seemed to benefit from Gabapentin treatment without showing any side effects. Although literature review yields many results for arachnoid cysts, no information regarding the algorithm of diagnosis and follow-up of such patients has been published.

Symptoms such as resistance to conservative treatment, deterioration of the neurological status or increase in the arachnoid cyst size should alert the surgeon of the requirement for an urgent surgical intervention. However, tolerable symptoms and a normal neurological status is an indication of conservative follow-up. An excision through laminectomy or fenestration is the most commonly used surgical technique, whereas a cystoperitoneal shunt is more suitable for recurrent patients.

The literature review of spinal intradural arachnoid cysts reveals symptomatic patients, who underwent surgery, as well as asymptomatic patients, who were only followed up. However, no case has reported any kind of treatment to alleviate the patient's symptoms and improve their quality of life. In this case report, we report an adult patient diagnosed with a spinal intradural arachnoid cyst, who did not undergo surgery but benefited from Gabapentin treatment.

\section{Ethics}

Informed Consent: Informed consent was obtained from the patient.

\section{Authorship Contributions}

Concept: H.K.A., A.K., O.G., Design: H.K.A., A.K., O.G., Data Collection or Processing: H.K.A., A.G.G., M.Ö.Ö., Analysis or Interpretation: H.K.A., A.G.G., M.Ö.Ö., Literature Search: H.K.A., A.K., M.Ö.Ö., O.G., Writing: H.K.A.

Conflict of Interest: No conflict of interest was declared by the authors.

Financial Disclosure: The authors declared that this study received no financial support.

\section{REFERENCES}

1. Kazan S, Özdemir O, Akyüz M, Tuncer R. Spinal intradural arachnoid cysts located anterior to the cervical spinal cord. Report of two cases and review of the literature. J Neurosurg. 1991;(2 Suppl) 211-15.

2. Endo H, Takanashi T, Shimizu H, Tominaga T. Thoracic Intradural Arachnoid Cyst Associated With Surgical Removal of Epidural Hematoma - Case Report. Neurol Med Chir (Tokyo). 2004;44:607-10.

3. Bond EA, Zada G, Bowen I, McComb JG, Krieger MD. Spinal arachnoid cysts in the pediatric population: report of 31 cases and a review of the literature. J Neurosurg Pediatrics. 2002;432-41.

4. Mohindra S, Gupta R, Bal A. Intra-dural spinalarachnoid cysts: a short series of 10 patients. Br J Neurosurg. 2010; 24:679-83.

5. da Conceição Araújo Filho $\mathrm{S}$, Brito da Silva $\mathrm{H}$, Freitas de Albuquerque LA, Cavalcante de Almeida JP, de Paiva Santos F, Sciubba DM. Giant intradural extramedullary arachnoid cyst of the thoracic spine. J Clin Neurosci. 2009;16:1369-71.

6. Wenger M, Zobor N, Markwalder R, Vogt E, Markwalder TM. Intradural extramedullary arachnoid cyst of the thoracic spine associated with cord compression. J Clin Neuroscience. 2007; 14:693-6.

7. Rao Z, Li J, Hang S, You C. Case Report Congenital spinal intradural arachnoid cyst associated with intrathoracic meningocele in a child. I Zhejiang Univ Sci B. 2010;11:429-32.

8. Novegno F, Umana G, MD, Di Muro L, Fraioli B, Fraioli MF. Case Report Spinal intramedullary arachnoid cyst: case report and literature review. The Spine Journal. 2014;14:e9-15.

9. Osenbach RK, Godersky JC, Traynelis VC, Schelper RD. Intradural extramedullary cysts of the spinal canal: clinical presentation, radiographic diagnosis, and surgical management. Neurosurgery. 1992;30:35-42.

10. Wang MY, Levi AD, Green BA. Intradural spinal arachnoid cysts in adults. Surg Neurol. 2003;60:49-55.

11. Van Nuenen B, Grotenhuis A, Vliet TV, Gijtenbeek A. Spinal cord compression by an arachnoid cyst: a case report and review of the literature. Zentralbl Neurochir. 2008;69:155-7.

12. Payera M, Brühlhart K. Case Report Spinal extradural arachnoid cyst: Review of surgical techniques. Journal of Clinical Neuroscience 2011;18:559-60.

13. Kumar K, Malik S, Schulte PA. Symptomatic spinal arachnoid cysts: report of two cases with review of the literature. Spine (Phila Pa 1976). 2003;28:E25-9.

14. Peruzzotti-jametti L, Ferrari S, Politi LS, Snider S, Mammi S, Comi G, et al. Giant anterior arachnoid cyst associated with syringomyelia: implications for treatment and follow- up. Spine (Phila Pa 1976). 2010;35:E322-4. 